\title{
Níveis de energia digestível sobre os desempenhos reprodutivo e zootécnico e a deposição de lipídios nos hepatócitos de machos de tilápia-do-nilo
}

\section{Robie Allan Bombardelli ${ }^{1}$, Carmino Hayashi ${ }^{2}$, Maria Raquel Marçal Natali ${ }^{3}$, Eduardo Antônio Sanches ${ }^{4}$, Pitágoras Augusto Piana ${ }^{5}$}

\author{
1 Universidade Estadual do Oeste do Paraná \\ 2 Instituto de Pesca. \\ 3 Universidade Estadual de Maringá. \\ ${ }^{4}$ Universidade Estadual Paulista. \\ ${ }^{5}$ Universidade Estadual do Oeste do Paraná.
}

RESUMO - O experimento foi conduzido com o objetivo de avaliar o desempenho reprodutivo e zootécnico e a deposição de lipídios no tecido hepático de machos de tilápia-do-nilo alimentados com rações contendo diferentes níveis de energia digestível, obtidos com a inclusão de óleo de soja. Foram utilizados 400 reprodutores (300 fêmeas e 100 machos) distribuídos em delineamento inteiramente casualizado, composto de cinco níveis de energia digestível $(2.700,2.950,3.200$, 3.450 e $3.700 \mathrm{kcal} . \mathrm{kg}$ de ração ${ }^{-1}$ ) e quatro repetições. Os reprodutores foram alimentados com rações contendo $35 \%$ de proteína bruta e submetidos ao manejo reprodutivo em hapas por 101 dias. O melhor resultado de concentração espermática e percentual de espermatozoides normais foram obtidos para reprodutores alimentados com rações contendo $3.465,56 \mathrm{e}$ $3.443,43 \mathrm{kcal}$. $\mathrm{kg}$ de ração ${ }^{-1}$, que produziram $7,98 \times 10^{9}$ espermatozoides.mL de sêmen-1 e 38,98\% de espermatozoides normais, respectivamente. A produção de sêmen, o pH seminal, o índice de sobrevivência espermática e o tempo de ativação espermática não foram afetados pelos níveis energéticos das rações. Os níveis de energia das rações não influenciaram o desempenho zootécnico dos peixes, mas promoveram aumento linear na deposição de lipídios nos hepatócitos e afetaram a qualidade seminal, estimulando a produção de espermatozoides e a melhora dos índices de normalidade da morfologia espermática em níveis energéticos próximos a $3.450 \mathrm{kcal}$. kg de ração-1.

Palavras-chave: fígado, nutrição, Oreochromis niloticus, peixes, reprodução, sêmen

\section{Digestible energy level on reproductive and zootechnical performance and lipids deposition in hepatocytes of the Nile tilapia males}

\footnotetext{
ABSTRACT - This experiment was carried out to evaluate the reproductive and zootechnical performance, and lipid deposition in the liver tissue of the Nile tilapia males fed diets containing different levels of digestible energy obtained from inclusion of soybean oil. Four hundred 400 broodfish (300 females and 100 males) were assigned to a completely randomized design composed of five levels of digestible energy $(2,700,2,950,3,200,3,450$ and 3,700 kcal digestible energy.kg of feed ${ }^{-1}$ ) and four replications. The breeding were fed diets containing $35 \%$ of crude protein and submitted to hapas reproductive management for 101 days. The model adjusted by multiple regression analysis suggests the best result for sperm concentration and percentage of normal sperm for breeding fed diets containing 3.465 .56 and $3.443 .43 \mathrm{kcal}$ digetible energy.kg of feed $^{-1}$, producing $7.98 \times 10^{9}$ sperm.mL of semen ${ }^{-1}$ and $38.98 \%$ of normal sperm, respectively. The diet energy levels also caused an increase of lipid inclusion in the hepatocytes. The sperm production, seminal $\mathrm{pH}$, sperm survival index and sperm activation time were not affected by energetic levels of the diets. The zootechnical performance was not affected by the energy levels of the diets either. The energy levels in the diets caused a linear increase in the lipid inclusion in the hepatocytes and affected the sperm quality by stimulating the spermatozoa production and the improving of normality indices of sperm morphology in energy levels around 3,450 kcal digestible energy.kg of feed ${ }^{-1}$.
}

Key Words: fish, liver, nutrition, Oreochromis niloticus, reproduction, sperm 


\section{Introdução}

Informações sobre a alimentação e nutrição de peixes, especialmente para as tilápias, são relativamente abundantes para as fases de crescimento (NRC, 1993; Santiago \& Laron, 2002, Meurer et al., 2008). Entretanto, pesquisas com nutrição de reprodutores ainda são escassas, principalmente em decorrência de fatores mercadológicos (Bhujel, 2000) e dificuldades impostas na condução dos experimentos (Brooks et al., 1997; VassaloAgius et al., 2001a).

Estudos relacionados às exigências de energia digestível para peixes tem sido realizados em várias espécies e fases de criação (Pezzato et al., 2000; Boscolo et al., 2005; Navarro et al., 2006; Navarro et al., 2007). Contudo, informações precisas acerca das exigências de energia digestível para dietas de reprodutores de tilápia-do-nilo ainda são inexistentes (Bhujel, 2000).

Sabe-se que as dietas influenciam a produção e a qualidade espermática (Billard et al., 1995; Vassalo-Agius et al., 2001b) e seminal (Ferrell, 1991; Watanabe \& VassaloAgius, 2003). Entretanto, na tilapicultura, a maioria das pesquisas com nutrição de reprodutores, estão voltadas para a avaliação do desempenho reprodutivo das fêmeas (Al-Hafedh et al., 1999; Fontaínhas-Fernandes et al., 2000; El-Sayed et al., 2003; El-Sayed et al., 2005; Pereira et al., 2009; Bombardelli et al., 2009). Para os machos de espécies de peixes utilizados na aquicultura, os poucos trabalhos existentes avaliam efeitos de fatores anti nutricionais (Salaro et al., 1999; Rinchard et al. 2002) ou os efeitos de ácidos graxos poliinsaturados sobre o desempenho reprodutivo (Asturiano et al., 2001).

Estudos visando à melhoria da qualidade dos gametas masculinos devem ser ampliados, uma vez que os gametas garantem o sucesso reprodutivo, contribuindo na fertilização natural ou artificial, principalmente no processo intra-ovocitário de inicialização do desenvolvimento embrionário (Coward et al., 2002). A manutenção da qualidade nutricional dos reprodutores também afeta o funcionamento e a morfologia de órgãos como o fígado, importante no metabolismo e no fornecimento de energia (Caballero et al., 2004).

Este trabalho foi conduzido com o objetivo de avaliar os desempenhos reprodutivo e zootécnico e a deposição de lipídios no tecido hepático de machos de tilápia-donilo (Oreochromis niloticus L.) alimentados com rações contendo diversos níveis de energia digestível, obtidos por meio pela inclusão de óleo de soja na dieta.

\section{Material e Métodos}

O experimento foi realizado entre 11 de janeiro a 22 de abril de 2005, totalizando 101 dias, no Laboratório de Tecnologia da Reprodução dos Animais Aquáticos Cultiváveis da Universidade Estadual do Oeste do Paraná, no Centro de Pesquisa em Aquicultura Ambiental do Instituto Ambiental do Paraná, por meio do convênio IAP/UNIOESTE e, no Laboratório de Histotécnica Animal do Departamento de Ciências Morfofisiológicas da Universidade Estadual de Maringá.

Foram utilizados 400 reprodutores de tilápia-do-nilo (Oreochromis niloticus), linhagem tai-chitralada: 300 fêmeas $(112,82 \pm 3,23 \mathrm{~g})$ e 100 machos $(146,06 \pm 3,43 \mathrm{~g})$. Os peixes foram alojados em hapas de malha $1 \mathrm{~mm} \times 4 \mathrm{~mm}$ e distribuídos aleatoriamente em dois viveiros escavados com dimensões de $20 \mathrm{~m} \times 10 \mathrm{~m}$.

As fêmeas foram estocadas em 20 hapas de dimensões $3 \mathrm{~m} \times 2 \mathrm{~m}$, em densidade de estocagem de 2,5 animais. $\mathrm{m}^{-2}$, totalizando 15 animais por hapa. Os machos foram estocados em outros 20 hapas de dimensões $2 \mathrm{~m} \times 1 \mathrm{~m}$, em densidade de estocagem de 2,5 animais. $\mathrm{m}^{-2}$, totalizando cinco animais por "hapa", respeitando a proporção entre os sexos de 1 macho para 3 fêmeas (Little \& Hulata, 2000).

Os animais foram distribuídos em delineamento inteiramente casualizado, composto de rações contendo cinco níveis de energia digestível e quatro repetições. As rações eram isoproteicas, com $35 \%$ de proteína bruta (Bhujel et al., 2001), e continham cinco níveis de energia digestível correspondentes a $2.700 ; 2.950 ; 3.200 ; 3.450 \mathrm{e}$ $3.700 \mathrm{kcal}$ de energia digestível.kg de ração-1 (Tabela 1). Foi considerado uma unidade experimental um hapa de $2 \mathrm{~m} \times 1 \mathrm{~m}$ contendo cinco machos.

Os reprodutores foram alimentados diariamente duas vezes ao dia (El-Sayed et al., 2005), às $10 \mathrm{~h}$ e às $16 \mathrm{~h}$, com taxa de arraçoamento de 1\% da biomassa ao dia (Bhujel, 2000), que foi corrigida a cada 17 dias a partir de biometrias. Os ingredientes utilizados na composição das rações foram triturados em moinho de martelo, utilizando-se peneira de 0,5 mm (Hayashi et al., 1999; Meurer et al., 2005).

Durante o período que precedeu a coleta dos dados (condicionamento), machos e fêmeas foram submetidos ao manejo reprodutivo com isolamento e descanso reprodutivo por 12 dias (Tacon et al., 1996). Após este período, os machos foram transferidos para os hapas das fêmeas para o acasalamento, que teve duração de cinco dias. Ao término do acasalamento, foi realizada a colheita dos ovos (MacIntosh \& Little, 1995) e mensurados o peso e o 
Tabela 1 - Composição das rações experimentais com diferentes níveis de energia digestível para reprodutores de tilápia-do-nilo

\begin{tabular}{|c|c|c|c|c|c|}
\hline \multirow[t]{2}{*}{ Alimento $(\%)$} & \multicolumn{5}{|c|}{ Energia digestível (kcal.kg de ração ${ }^{-1}$ ) } \\
\hline & 2.700 & 2.950 & 3.200 & 3.450 & 3.700 \\
\hline Farelo de soja ${ }^{a}$ & 70,75 & 70,02 & 70,91 & 71,81 & 72,70 \\
\hline Óleo de $\operatorname{soja}^{\mathrm{a}}$ & 0,00 & 0,61 & 5,21 & 9,80 & 14,39 \\
\hline Sabugo de milho & 7,11 & 0,00 & 0,00 & 0,00 & 0,00 \\
\hline Fosfato bicálcico & 1,84 & 1,77 & 1,81 & 1,85 & 1,90 \\
\hline Sal comum & 0,50 & 0,50 & 0,50 & 0,50 & 0,50 \\
\hline Antioxidante (BHT) & 0,01 & 0,01 & 0,01 & 0,01 & 0,01 \\
\hline \multicolumn{6}{|l|}{ Nutrientes } \\
\hline Cálcio (\%) & 1,00 & 1,00 & 1,00 & 1,00 & 1,00 \\
\hline Fosforo total $(\%)$ & 0,80 & 0,80 & 0,80 & 0,80 & 0,80 \\
\hline Cinzas $(\%)$ & 8,43 & 8,34 & 8,35 & 8,35 & 8,35 \\
\hline Proteína digestível (\%) & 31,12 & 31,33 & 31,31 & 31,30 & 31,28 \\
\hline Proteína bruta $(\%)$ & 35,00 & 35,00 & 35,00 & 35,00 & 35,00 \\
\hline Relação energia digestível:proteína digestível (kcal:g) & 8,68 & 9,42 & 10,22 & 11,02 & 11,83 \\
\hline
\end{tabular}

a De acordo com os valores de digestibilidade de Boscolo et al. (2002).

${ }^{1}$ Níveis de garantia por quilograma do produto (Rovimix peixes): vit. A - 500.000 UI; vit. D3 - 200.000 UI; vit. E - 5.000 mg; vit. K3 - 1.000 mg; vit. B1 - 1.500 mg; vit. B2 - $1.500 \mathrm{mg}$; vit. B6 - $1.500 \mathrm{mg}$; vit. B12 - $4.000 \mathrm{mg}$; ácido fólico - $500 \mathrm{mg}$; pantotenato cálcio - $4.000 \mathrm{mg}$; vit. C - $15.000 \mathrm{mg}$; biotina - $50 \mathrm{mg}$; inositol - 10.000 ; nicotinamida - 7.000; colina - $40.000 \mathrm{mg}$; cobalto - $10 \mathrm{mg}$; cobre - $500 \mathrm{mg}$; ferro - $5.000 \mathrm{mg}$; iodo - $50 \mathrm{mg}$; manganês - $1.500 \mathrm{mg}$; selênio - $10 \mathrm{mg}$; zinco - $5.000 \mathrm{mg}$.

comprimento padrão dos animais de ambos os sexos, por meio de balança digital e ictiômetro, de precisão $0,01 \mathrm{~g}$ e $0,1 \mathrm{~cm}$, respectivamente. Em seguida, os reprodutores foram novamente separados em seus respectivos hapas. Esse procedimento foi repetido por 93 dias a fim de condicionar os animais ao manejo reprodutivo e manter os machos em atividade reprodutiva.

Diariamente, pela manhã, a amplitude térmica $\left({ }^{\circ} \mathrm{C}\right)$ foi mensurada por meio de um termômetro de máxima e mínima, com precisão de $\pm 1{ }^{\circ} \mathrm{C}$. Quinzenalmente, em horários predeterminados, foram mensurados nos tanques onde estavam contidos os hapas os teores de oxigênio dissolvido da água (oxímetro digital Hanna F-HI 9147), às 6 h, e o pH da água (pHmetro digital Hanna F-HI 8424), às 6 h e às 16 h.

Para controlar a produtividade primária nos viveiros de criação e sua influência na nutrição das tilápias, não foi utilizado nenhum tipo de adubação. Além disso, o abastecimento de água (proveniente do rio São Francisco Falso) foi controlado de modo a impedir o desenvolvimento de fitoplâncton.

Após 93 dias de experimento, os peixes foram sedados por imersão em solução contendo óleo de cravo (Taylors \& Roberts, 1999), a uma concentração de $63 \mathrm{mg} . \mathrm{L}^{-1}$, por três minutos (adaptado de Bard et al., 2004). Em seguida, foram mensurados individualmente o peso e o comprimento padrão, além dos parâmetros de qualidade seminal e espermática.

A colheita de sêmen foi realizada por meio de aplicação de massagem abdominal nos reprodutores, no sentido céfalocaudal. A primeira porção do sêmen coletado foi desprezada para evitar possível contaminação com urina. $\mathrm{O}$ volume total e relativo ao peso corporal de sêmen liberado por cada macho foi mensurado pela colheita do material em seringas de insulina de volume útil de $1,0 \mathrm{~mL}$ e precisão de $0,01 \mathrm{~mL}$ (adaptado de Godinho et al., 2003).

Para manipulação do sêmen, utilizou-se o procedimento descrito por Asturiano et al. (2001), de modo que o material colhido foi conservado em gelo $\left( \pm 12^{\circ} \mathrm{C}\right)$ durante o tempo necessário para a realização das análises de qualidade do sêmen.

$\mathrm{O}$ pH seminal foi mensurado pelo método colorimétrico, utilizando-se o papel de tornassol.

O tempo de ativação espermática foi mensurado, individualmente e em triplicata, de cada colheita proveniente de um único peixe. Para esta avaliação, $5 \mu \mathrm{L}$ de sêmen foram diluídos em $200 \mu \mathrm{L}$ de solução ativadora (água a $26^{\circ} \mathrm{C}$ ) e desta mistura, $5 \mu \mathrm{L}$ foram observados em microscópio de luz em objetiva 40X. O parâmetro mensurado foi o intervalo do início da ativação à perda de motilidade de aproximadamente $50 \%$ dos espermatozoides (adaptado de Asturiano et al., 2001).

A avaliação do índice de sobrevivência espermática foi realizada a partir método de coloração eosina-nigrosina (Kavamoto \& Fogli da Silveira, 1986; Bombardelli et al., 2006). No entanto, utilizaram-se $30 \mu \mathrm{L}$ de sêmen e $90 \mu \mathrm{L}$ de cada corante, para a realização da mistura e posteriormente confecção do esfregaço (adaptado de Murgas et al., 2003). Após o processamento das lâminas, o material foi analisado 
em microscópio de luz em objetiva de 40X, contando-se um número total de 400 espermatozoides de cada colheita, proveniente de um único peixe. Foram consideradas células espermáticas mortas aquelas que apresentaram coloração vermelha ou rosada, decorrente da absorção dos corantes, e vivas aquelas sem coloração, por serem impermeáveis aos corantes.

A mensuração da concentração espermática (Billard et al., 1995) foi realizada individualmente e em triplicatas, em microscópio de luz em objetiva de 40X pelo método de contagem de células espermáticas em câmara hematimétrica de Neubauer (Mylonas et al., 1997). Neste procedimento, amostras de sêmen foram fixadas em solução de formol salina tamponada (diluição de 1:1000).

Do material anteriormente fixado em solução de formol salina tamponada, foram realizados dois esfregaços, fixados a temperatura ambiente, para avaliação e mensuração dos índices de alterações morfológicas dos espermatozoides (Rurangwa et al., 2004; Streit Jr. et al., 2005). As lâminas obtidas com os esfregaços foram submetidas à coloração em rosa de bengala (Hafez \& Hafez, 2004; Streit Jr. et al., 2004) e, em seguida, analisadas em microscópio de luz em objetiva 40X, avaliando-se um total de 400 espermatozóides de cada colheita proveniente de um único peixe. Os espermatozoides avaliados foram classificados como normais ou com alterações morfológicas primárias ou secundárias (adaptado de CBRA, 1998; Chenoweth, 2005; Streit Jr. et al., 2006).

Após a colheita de sêmen, os reprodutores foram novamente estocados em seus respectivos hapas, por um período de oito dias para descanso reprodutivo. Em seguida, foram sedados, conforme descrito anteriormente e, submetidos a eutanásia por meio de choque térmico, pela imersão em água contendo gelo, aproximadamente $1{ }^{\circ} \mathrm{C}$.

Os peixes foram individualmente pesados e medidos quanto ao comprimento padrão e dissecados para obtenção dos pesos das gônadas, do fígado e das vísceras.

A partir destes dados foram avaliados os parâmetros zootécnicos de peso médio final, comprimento padrão médio final, ganho de peso médio (GPM = peso final-peso inicial), ganho de peso médio diário (GPMD = ganho de peso/dias de criação), conversão alimentar aparente $(\mathrm{CAA}=\mathrm{g}$ de ração consumida/g de ganho de peso $)$ e índices gonadossomático (IGS = (peso da gônada/peso corporal $) \times 100)($ adaptado de Vazzoler, 1996) hepatossomático $($ IHS $=($ peso do fígado/peso corporal $) \times$ $100)$ e viscerossomático (IVS = (peso das visceras/peso corporal) $\times 100$ ) .

Dos animais dissecados, foram separados aleatoriamente dois fígados de machos de cada unidade experimental para avaliação histológica e determinação do percentual de inclusão lipídica, totalizando oito fígados analisados para cada nível energético das rações.

Esses órgãos foram coletados e fixados em solução de Bouin aquoso por um período de 8 horas e transferidos, em seguida, para solução de álcool a 70\%. Posteriormente, o material foi desidratado em séries crescentes de álcool, diafanizadas em xilol e incluídos em parafina para obtenção de cortes semisseriados transversais com $5 \mu \mathrm{m}$ de espessura.

De cada fígado, foram confeccionadas quatro lâminas contendo cinco cortes histológicos e organizados de modo que, na sequência, o primeiro corte foi utilizado para coloração com hematoxilina-eosina e o corte seguinte com ácido periódico de Schiff (PAS). Esse procedimento garantiu a preparação de duas lâminas por animal para cada método de coloração. Dessas lâminas, foram utilizados para as análises morfométricas cinco corte histológicos de cada coloração por animal, totalizando, para cada nível de energia, 40 campos microscópicos corados em hematoxilina-eosina e outros 40 campos corados em ácido periódico de Schiff.

Para estimar o percentual de inclusão lipídica, realizou-se análise morfométrica tomando-se como medida padrão a área total do campo microscópico $\left(32.690,43 \mu \mathrm{m}^{2}\right)$ (Figura 1 A1) subtraída da área ocupada pela veia centro-lobular (Figura 1 A2), sinusoides, núcleos e nucléolos (L1) (Figura 1 B1 e B2). Definindo-se esta área, em seguida, foi determinada a área marcada por glicogênio (L2) (Figura $1 \mathrm{C} 1$ e C2). A diferença entre as áreas L1 e L2 indicou a área ocupada por lipídios.

A análise morfométrica foi realizada por meio de microscópio de luz Zeiss, em objetiva de 40X e as 400 imagens obtidas e analisadas pelo pacote de análise de imagens Image Pro-Plus $4.5^{\circledR}$.

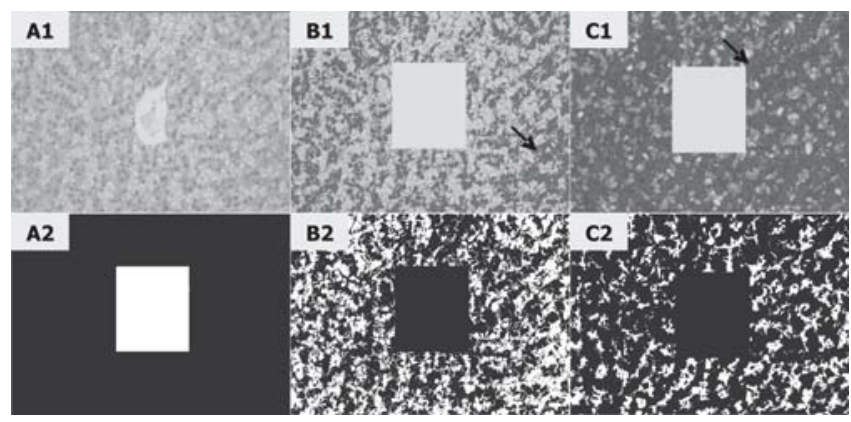

$\mathrm{A} 1$ = campo microscópico (H.E) B1 = área ocupada por sinusoídes, núcleos e nucléolos (HE). C1 = área ocupada por glicogênio (PAS). A2, B2, C2 = negativos das imagens A1, B1, C1. Setas indicam a área marcada pelo software Image Pró-Plus $4.5^{\circledR}$.

Figura 1 - Análise morfométrica do fígado de peixes. 
Os dados obtidos foram inicialmente submetidos à análise de variância multivariada (MANOVA) a 5\% de significância. Em caso de evidência de efeito significativo, foi aplicada a análise de variância (ANOVA), individualmente, para cada variável-resposta a 5\% de significância. As variáveis que sofreram efeito dos níveis de energia digestível das rações foram submetidas ao protocolo de regressão linear múltipla do software Statistica $7.0{ }^{\circledR}$.

\section{Resultados e Discussão}

A temperatura da água apresentou valores médios, mínimos e máximos, de $26,7 \pm 1,0$ e $30,2 \pm 1,2^{\circ} \mathrm{C}$ e a concentração média de oxigênio dissolvido foi de $6,11 \pm 1,05 \mathrm{mg} . \mathrm{L}^{-1}$, ou seja, adequados para a reprodução de fêmeas de tilápia (Bhujel, 2000). Os valores médios de $\mathrm{pH}$ da água foram 7,50 $\pm 0,09$ pela manhã e 9,33 $\pm 0,06$ pela tarde, os quais são adequados para bom o crescimento da espécie (Little \& Hulata, 2000; Ross, 2000). Contudo, não existem informações se o nível de oxigênio dissolvido adequado para reprodutores machos corresponde aos das fêmeas e se o intervalo de $\mathrm{pH}$ adequado para o crescimento também o é para a reprodução (Bhujel, 2000).

Os níveis de energia digestível das rações influenciaram os parâmetros espermáticos (Tabela 3), e o modelo ajustado pela análise de regressão múltipla da variável concentração espermática sugere que o resultado teórico de máximo desempenho reprodutivo seja alcançado para reprodutores alimentados com rações contendo $3.465,56$ kcal de energia digestível. $\mathrm{kg}$ de ração ${ }^{-1}$ produzindo $7,98 \times 10^{9}$ espermatozóides.mL de sêmen

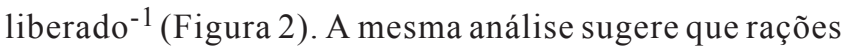
contendo 3.443,43 kcal de energia digestível.kg de ração ${ }^{-1}$ proporcionaram máximo índice de normalidade espermática de 39,18\% (Figura 3).

As análises histológicas também evidenciaram efeito das rações $(\mathrm{P}<0,05)$ sobre o percentual de inclusão lipídica, com relação diretamente proporcional entre os níveis de energia digestível das rações e o percentual de inclusão lipídica nos hepatócitos (Figura 4).

Asturiano et al. (2001) verificaram aumento significativo na produção de sêmen, no percentual de machos em espermiação, na concentração e na motilidade espermática em reprodutores de "sea bass" (Dicentrarchus labrax) alimentados com rações contendo baixas relações entre os ácidos graxos n-3:n-6.

Provavelmente, o elevado nível de energia proveniente das rações experimentais neste trabalho tenha estimulado a produção de células espermatogênicas, como verificado em suínos por Oliveira Silva et al. (1998), que relataram aumento da produção e da normalidade das células espermáticas.

Navarro et al. (2006) também verificaram que níveis crescentes de energia digestível em rações para alevinos de piauçu (Leporinus macrocephalus) interferem no desenvolvimento testicular, uma vez que os maiores níveis testados $(2.800$ e $2.900 \mathrm{kcal}$ de ED.kg de ração-1 $)$ promoveram aumento no número de espermatogônias e a formação de cistos de espermatogônias primárias e secundárias, circundadas por maior quantidade de células de Sertoli.

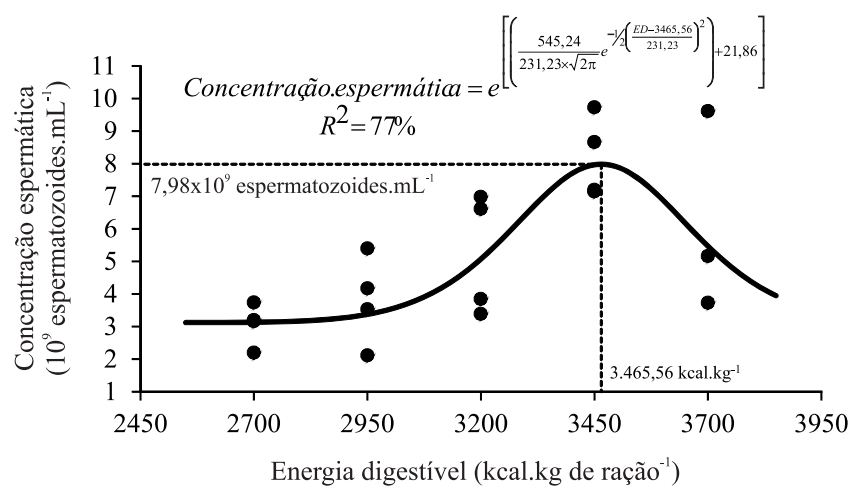

Figura 2 - Concentração espermática no sêmen de tilápia-do-nilo (Oreochromis niloticus L.) alimentadas com diferentes níveis de energia digestível na ração.

Tabela 3 - Desempenho reprodutivo de machos de tilápia-do-nilo (Oreochromis niloticus L.) alimentados com rações contendo diversos níveis de energia digestível

\begin{tabular}{|c|c|c|c|c|c|c|}
\hline \multirow[t]{2}{*}{ Variável } & \multicolumn{5}{|c|}{ Energia digestível (kcal.kg de ração ${ }^{-1}$ ) } & \multirow[b]{2}{*}{$\mathrm{P}$} \\
\hline & 2.700 & 2.950 & 3.200 & 3.450 & 3.700 & \\
\hline Volume médio de sêmen (mL) & 0,47 & 0,244 & 0,37 & 0,26 & 0,19 & 0,19 \\
\hline $\mathrm{pH}$ seminal & 7,53 & 7,61 & 7,49 & 7,70 & 7,53 & 0,83 \\
\hline Concentração espermática (espermatozoides $\times 10^{9} \cdot \mathrm{mL}^{-1}$ ) & 3,08 & 3,80 & 5,21 & 8,19 & 6,17 & 0,01 \\
\hline Espermatozoides normais (\%) & 23,76 & 28,63 & 29,93 & 39,07 & 29,65 & 0,00 \\
\hline \multicolumn{7}{|l|}{ Espermatozoides anormais (\%) } \\
\hline Anormalidade secundária (\%) & 10,64 & 9,53 & 10,50 & 9,59 & 16,15 & 0,57 \\
\hline Tempo de ativação espermática (s) & 52,59 & 45,62 & 45,79 & 47,30 & 55,20 & 0,58 \\
\hline Índice de sobrevivência espermática (\%) & 97,36 & 97,35 & 98,01 & 96,76 & 97,21 & 0,76 \\
\hline
\end{tabular}




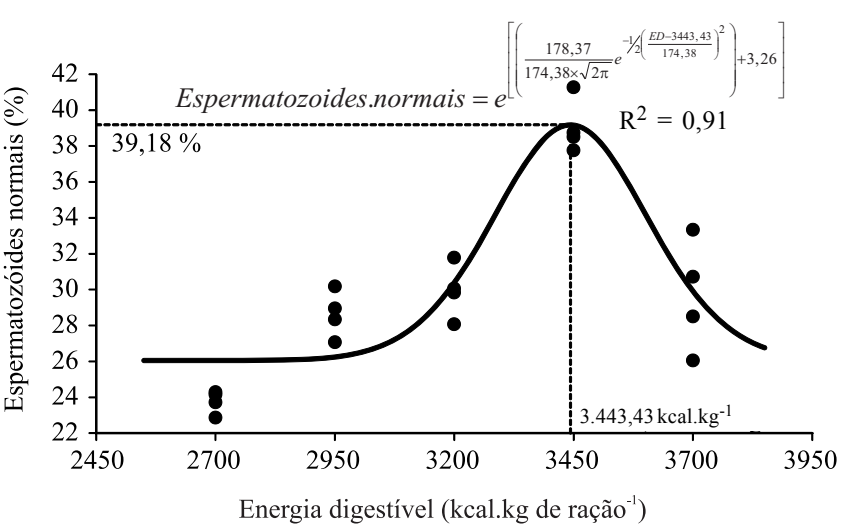

Figura 3 - Percentual de espermatozoides normais em sêmen de tilápia-do-nilo (O. niloticus, L.) alimentados com rações contendo diferentes níveis de energia digestível.

Os resultados de Cerdà et al. (1997) corroboram parcialmente as sugestões anteriores, quando os níveis energéticos das rações são obtidos pela inclusão de óleos. Esses autores verificaram que os ácidos graxos poliinsaturados promovem em "sea bass" (Dicentrarchus labrax) aumento nos percentuais de machos em espermiação e dos níveis plasmáticos do andrógeno 11-cetotestosterona, hormônio esteroide fundamental para a espermatogênese e formação do esperma (Redding \& Patiño, 1993; Baldisserotto, 2002), especialmente pela sua influência na produção da activina B, indutora da proliferação das espermatogônias (Van Der Kraak et al., 1997).

Os reduzidos percentuais de concentração e normalidade espermática quando impostos baixos níveis energéticos da ração (Figuras 2 e 3 ) podem estar relacionados à fatores que influenciam na maturação testicular, como a redução da ocorrência de espermatogônias e células de Sertoli (Navarro et al., 2006). Semelhante ao que ocorre em mamíferos, esses efeitos podem ter ainda relação com a redução da resposta dos testículos às gonadotrofinas (Ferrel, 1991). Por outro lado, o mesmo efeito verificado em

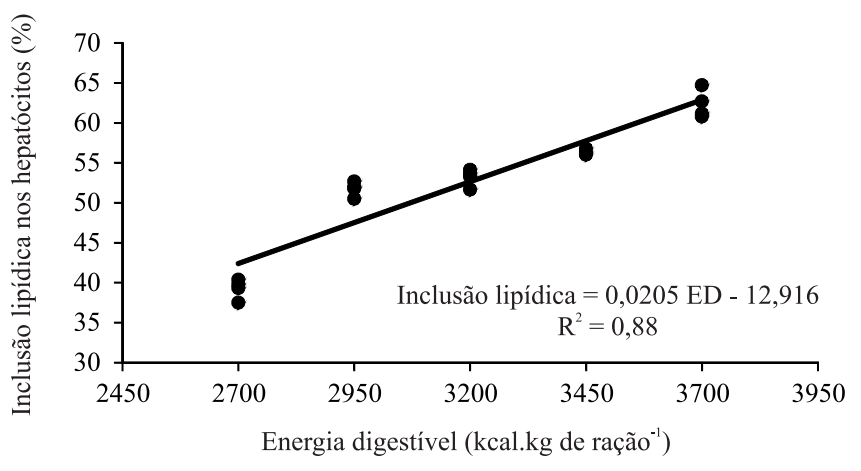

Figura 4 - Área percentual de inclusão de lipídeos em hepatócitos de machos de tilápia-do-nilo (O. niloticus, L.) alimentados com rações contendo diferentes níveis de energia digestível.

elevados níveis de energia da ração (Figuras 2 e 3 ) possivelmente não está associado à limitação da ingestão da ração (Pezzato et al., 2004) nem à redução do consumo de nutrientes (Bhujel, 2000), uma vez que o desempenho zootécnico (Tabela 4) dos animais não foi afetado $(\mathrm{P}>0,05)$ pelas rações.

Outros fatores podem ter contribuído para a redução da concentração e da normalidade espermática (Figuras 2 e 3), entre eles, a perda de energia metabólica e até mesmo de toxicidades pelo excesso de energia nas rações após a inclusão de óleo de soja. Essa hipótese pode ser confirmada pelos resultados das análises histológicas dos fígados dos machos (Figura 4), que comprovaram que o aumento dos níveis de energia nas rações elevou $(\mathrm{P}<0,05)$ a deposição de lipídeos nos hepatócitos.

Caballero et al. (2004) estudaram os efeitos da substituição do óleo de peixe pelo de soja em rações para "sea bream" (Sparus aurata L.) e verificaram que o uso de maiores níveis de óleo de soja nas rações provocou alterações histológicas do tecido hepático, especialmente aumento do volume de lipídeos e a ocorrência de quadros clínicos de

Tabela 4 - Desempenho zootécnico de machos de tilápia-do-nilo alimentados com rações contendo diversos níveis de energia digestível

\begin{tabular}{|c|c|c|c|c|c|c|}
\hline \multirow[t]{2}{*}{ Variável } & \multicolumn{5}{|c|}{ Energia digestível (kcal.kg de ração ${ }^{-1}$ ) } & \multirow[b]{2}{*}{$\mathrm{P}$} \\
\hline & 2.700 & 2.950 & 3.200 & 3.450 & 3.700 & \\
\hline Peso inicial médio (g) & 145,00 & 143,90 & 147,70 & 146,2 & 147,5 & 0,08 \\
\hline Comprimento padrão inicial $(\mathrm{cm})$ & 15,85 & 15,83 & 15,85 & 15,85 & 16,00 & 0,10 \\
\hline Peso final médio $(\mathrm{g})$ & 198,60 & 206,90 & 198,10 & 199,80 & 215,87 & 0,50 \\
\hline Comprimento padrão final $(\mathrm{cm})$ & 17,88 & 18,00 & 17,73 & 17,88 & 18,23 & 0,68 \\
\hline Ganho de peso médio $(\mathrm{g})$ & 53,60 & 63,00 & 50,40 & 53,60 & 71,50 & 0,65 \\
\hline Ganho de peso médio diário (g. dia $\left.{ }^{-1}\right)$ & 0,67 & 0,79 & 0,63 & 0,67 & 0,89 & 0,65 \\
\hline Conversão alimentar aparente $\left(\mathrm{g} \cdot \mathrm{g}^{-1}\right)$ & 2,19 & 2,23 & 2,79 & 2,99 & 2,09 & 0,41 \\
\hline Índice hepatossomático $(\%)$ & 1,49 & 1,43 & 1,74 & 1,52 & 1,45 & 0,06 \\
\hline Índice gonadossomatico (\%) & 0,86 & 1,02 & 0,87 & 0,76 & 0,87 & 0,43 \\
\hline Índice viscerossomatico $(\%)$ & 4,89 & 5,25 & 4,93 & 4,80 & 3,75 & 0,83 \\
\hline
\end{tabular}


esteatose nos hepatócitos. Ruyter et al. (2006) também verificaram efeitos semelhantes em salmão-do-atlântico (Salmo salar).

Tendo como base estudos realizados com ratos, Caballero et al. (2004) sugeriram que rações contendo óleo de soja podem aumentar a deposição lipídica nos hepatócitos, devido à atividade lipogênica desse óleo, e reduzir a oxidação de lipídeos pelo fígado de "sea bream" (Sparus aurata L.). Desta forma, estes quadros possivelmente promoveriam a perda ou redução da disponibilidade de energia metabólica.

Não foi evidenciado efeito dos níveis de energia digestível das rações $(\mathrm{P}>0,05)$ sobre os índices de anormalidades espermática primária e secundária (Tabela $3)$. Os resultados de anormalidade foram bastante elevados em todos os níveis de energia das rações e variaram de 51,35 a $65,60 \%$ e de 9,53 a $16,15 \%$ para as anormalidades primárias e secundárias, respectivamente (Tabela 3). Entre todas as anormalidades observadas, as mais frequentes foram cauda quebrada, cauda enrolada e cauda dobrada.

Índices de anormalidade espermática recomendados para a inseminação artificial ou monta natural em mamíferos são de no máximo 30\% (CBRA, 1998). Entretanto, esses valores não estão estabelecidos para o adequado sucesso da fertilização natural ou artificial de peixes (Moraes et al., 2004).

As anormalidades espermáticas têm sido relacionadas à infertilidade ou esterilidade na maioria das espécies de mamíferos (Mortimer, 2000; Chenoweth, 2005, Collodel \& Moretti, 2006). Especulações neste sentido são feitas quanto à fertilização em peixes (Kavamoto et al., 1999), mas não são conclusivas.

Estudos da morfologia espermática em peixes têm apresentado resultados variados quanto aos índices de normalidade, com valores de 16,28\% (Mataveli et al., 2007) para a tilápia-do-nilo (Oreochromis niloticus), de 90,46\% (Kavamoto et al., 1999) para o curimbatá (Prochilodus scrofa) e de 20,39\% para o pacu (Piaractus mesopotamicus) (Streit Jr. et al., 2006).

Neste estudo, os índices de sobrevivência espermática não foram afetados pelos níveis de energia das rações $(\mathrm{P}>0,05)$, mas os valores permaneceram relativamente elevados, variando de 96,76 a 98,01\% (Tabela 3). Esse parâmetro pode ser utilizado para avaliar a qualidade do sêmen, pois tem relação direta com a motilidade espermática (Kavamoto \& Fogli da Silveira, 1986; Bombardelli etal., 2006), a qual é um adequado indicador da qualidade do sêmen, mesmo que as taxas de fertilização sejam mais conclusivas (Coward et al., 2002).
A tilápia-do-nilo apresenta o mecanismo de inativação espermática por meio da composição seminal por glicoproteínas de elevado peso molecular (Coward et al., 2002). Assim, após o início da ativação dos espermatozoides em meio hipotônico, a motilidade espermática reduz, de modo irreversível, ao longo do tempo (Billard et al., 1995; Rana, 1995). Um dos mecanismos que controlam a ativação e o tempo de ativação espermática é o pH seminal (Coward et al., 2002). Tanto o pH seminal, quanto o tempo de ativação espermática não foram influenciados $(\mathrm{P}>0,05)$ pelos níveis de energia digestível impostos aos reprodutores e variaram de 7,53 a 7,70 e de 45,62 e 55,20 segundos, respectivamente (Tabela 3 ). Estes resultados de tempo de ativação são consideravelmente superiores aos observados em outras espécies, como a truta arco-íris, de 20 a 25 segundos (Izquierdo et al., 2001).

Os valores médios de peso final, de comprimento padrão final, dos ganhos de peso e de peso médio diário e de conversão alimentar aparente não foram influenciados $(\mathrm{P}>0,05)$ pelos níveis de energia das rações (Tabela 4). Esses resultados eram esperados, uma vez que o manejo alimentar foi adequado para o bom desempenho reprodutivo da espécie (Bhujel, 2000; Bhujel et al., 2001) e não para o crescimento. Isso pode ser verificado também pelos valores de conversão alimentar aparente (Tabela 4), que foram elevados (2,09 a 2,99 g. $\left.\mathrm{g}^{-1}\right)$, uma vez que os reprodutores de tilápia destinam grande parte das reservas energéticas à reprodução (Turner \& Robinson, 2000).

Asturiano et al. (2001) e Vassalo-Agius et al. (2001a) também não verificaram efeitos de rações suplementadas com ácidos graxos sobre o peso e o comprimento de reprodutores de "sea bass" (Dicentrarchus labrax) e de truta arco-íris (Oncorhynchus mikiss).

Os resultados dos índices hepatossomático, gonadossomático e viscerossomático são importantes, pois sugerem alterações morfológicas em resposta às rações, como por exemplo, maior atividade do órgão e/ou deposição de gorduras. Apesar de terem sido evidenciadas alterações do tecido hepático e das características seminais, os índices hepatossomático, gonadossomático e viscerossomático não foram influenciados $(\mathrm{P}>0,05)$ pelos níveis crescentes de energia digestível das rações (Tabela 4).

\section{Conclusões}

O aumento dos níveis de energia nas rações de reprodutores de tilápia-do-nilo acentua a deposição de lipídios nos hepatócitos, influencia a qualidade seminal, especialmente a produção de espermatozoides, e melhora 
os índices de normalidade da morfologia espermática em níveis energéticos próximos a $3.450 \mathrm{kcal}$ de energia digestível.kg de ração ${ }^{-1}$.

\section{Referências}

AL-HAFEDH, Y.S.; SIDDIQUI, A.Q.; AL-SAIADY, M.Y. Effects of dietary protein levels on gonad maturation, size and age at first maturity, fecundity and growth of Nile tilapia. Aquaculture International, v.7, p.319-332, 1999.

ASTURIANO, J.F.; SORBERA, L.A.; CARRILO, M. et al. Reproductive performance in male European sea bass (Dicentrarchus labrax, L.) fed two PUFA - enriched experimental diets: a comparison with males fed a wet diet. Aquaculture, v.194, p.173-190, 2001

BALDISSEROTTO, B. Fisiologia de peixes aplicada à piscicultura. Santa Maria: Editora UFSM, 2002. $211 \mathrm{p}$.

BARD, J.; ASSUMPČ̃̃O, L.; SCHAEFFER, L. et al. Emprego de óleo de cravo na indução à anestesia de juvenis de tilápia-do-Nilo (Oreochromis niloticus). In: SIMPOSIO PARANAENSE DE ENGENHARIA DE PESCA, 2., 2004, Toledo. Anais... Toledo: Simpósio Paranaense de Engenharia de Pesca/Gmosis, [2004] (CD-ROM).

BHUJEL, R. C. A review of strategies for the management of Nile tilapia (Oreochromis niloticus) broodfish in seed production systems, especially hapa-based systems. Aquaculture, v.181, p.37-59, 2000

BHUJEL, R.C.; YAKUPITIYAGE, A.; TURNER, W.A. et al. Selection of a commercial feed for Nile tilapia (Oreochromis niloticus) broodfish breeding in a hapa - in - pond system. Aquaculture, v.194, p.303-314, 2001.

BILLARD, R.; COSSON, J.; CRIM, L.W. et al. Sperm physiology and quality. In: BROMAGE, N. R.; ROBERTS, R. J. (Ed.) Broodstock management and egg and larval quality. London: Blackwell Science Ltd, 1995. p.25-52.

BOMBARDELLI, R.A.; MÖRSCHBÄCHER, E.F.; CAMPAGNOLO, R. et al. Dose inseminante para fertilização artificial de ovócitos de jundiá cinza, Rhamdia quelen (Quoy \& Gaimardm, 1824). Revista Brasileira de Zootecnia, v.35, n.4, p.1251-1257, 2006.

BOMBARDELLI, R.A.; HAYASHI, C.; NATALI, M.R.M. et al. Desempenho reprodutivo e zootécnico e deposição de lipídios nos hepatócitos de fêmeas de tilápia-do-nilo alimentadas com rações de diversos níveis energéticos. Revista Brasileira de Zootecnia, v.38, n.8, p.1391-1399, 2009.

BOSCOLO, W.R.; HAYASHI, C.; MEURER, F. Digestibilidade aparente da energia e nutrientes de alimentos convencionais e alternativos para o tilápia-do-Nilo (Oreochromis niloticus). Revista Brasileira de Zootecnia, v.31, n.2, p.539-545, 2002.

BOSCOLO, W.R.; SIGNOR, A.; FEIDEN, A. et al. Energia digestível para larvas de tilápia do Nilo (Oreochromis niloticus) na fase de reversão sexual. Revista Brasileira de Zootecnia, v.34, n.6, p.1813-1818, 2005 .

BROOKS, S.; TYLER, C.R.; SUMPTER, J.P. Egg quality in fish: what makes a good egg? Reviews in Fish Biology and Fisheries, v.7, p.287-416, 1997.

CABALLERO, M.J.; IZQUIERDO, M.S.; KJORSVIK, E. et al. Histological alterations in the liver of sea bream, Sparus auratus L., caused by short- or long - term feeding with vegetable oils as the sole lipid source. Journal of Fish Disease, v.27, p.531-541, 2004.

CERDÀ, J.; ZANUY, S.; CARRILO, M. Evidence for dietary effects on plasma levels of sexual steroids during spermatogenesis in the sea bass. Aquaculture International, v.5, p.473-477, 1997.

CHENOWETH, P.J. Genetic sperm defects. Theriogenology, v. 64, p.457-468, 2005.

COLÉGIO BRASILEIRO DE REPRODUÇÃO ANIMAL. Manual para exame andrológico e avaliação de sêmen animal. 2.ed. Belo Horizonte: CBRA, 1998. 49p.
COLlodel,G.; MORETTi, E. Sperm morphology and aneuploidies: defects of supposed genetic origin. Journal Compilation, v.38, p.208-215,2006.

COWARD, K.; BROMAGE, N.R.; HIBBITT, O. et al. Gamete physiology, fertilization and egg activation in teleost fish. Reviews in Fish Biology and Fisheries, v.12, p.33-58, 2002.

EL-SAYED, A.M.; MANSOUR, C.R.; EZZAT, A.A. Effects of dietary lipid source on spawning performance of Nile tilapia (Oreochromis niloticus) broodstock reared at different water salinities. Aquaculture, v.248, p.187-196, 2005.

EL-SAYED, A.M.; MANSOUR, C.R.; EZZAT, A.A. Effects of dietary protein level on spawning performance of Nile tilapia (Oreochromis niloticus) broodstock reared at different water salinities. Aquaculture, v.220, p.619-632, 2003.

FERRELL, C.L. Nutritional influences on reproduction. In: CUPPS, P.T. (Ed.) Reproduction in domestic animals. 4.ed. London: Academic Press, 1991. p.577-604.

FONTAÍNHAS-FERNANDES, A.; MONTEIRO, M.; FIGUEIREDO, A. et al. Partial or total replacement of fish meal by plant protein affects gonadal development and plasma $17 \mathrm{~b}$-estradiol levels in female Nile tilapia. Aquaculture International, v.8, p.299-313, 2000 .

GODINHO, H.P.; AMORIM, V.M.C.; PEIXOTO, M.T.D Criopreservação do sêmen de tilápia-nilótica Oreochromis niloticus, var. Chitralata: Crioprotetores, soluções ativadoras e refrigerador criogênico. Revista Brasileira de Zootecnia, v.32, n.6, p.1537-1543, 2003

HAFEZ, E.S.E; HAFEZ, B. Reprodução animal. 7.ed. Barueri: Manole, 2004. 509p.

HAYASHI, C.; BOSCOLO, W.R.; SOARES, C.M. et al. Uso de diferentes graus de moagem dos ingredientes em dietas para tilápia-do-Nilo (Oreochromis niloticus L.) na fase de crescimento. Acta Scientiarum, v.21, n.3, p.733-737, 1999.

IZQUIERDO, M.S.; FERNANDEZ-PALACIOS, H.; TACON, A.G.J. Effect of broodstock nutrition on reproductive performance of fish. Aquaculture, v.197, p.25-42, 2001.

KAVAMOTO, E.T.; BARNABE, V.H.; CAMPOS, B.E.S et al Anormalidades morfológicas nos espermatozóides do curimbatá, Prochilodus scrofa (STEINDACHNER, 1881) (OSTEICHTHYES, CHARACIFORMES, PROCHILODONTIDAE). Boletim do Instituto de Pesca, v.25, p.61-66, 1999.

KAVAMOTO, E.T.; FOGLI DA SILVEIRA, W. Características físicas, químicas e microscópicas do sêmen do bagre, Rhamdia hilari (valenciennes, 1840) em condições de campo. Boletim do Instituto de Pesca, v.13, p.95-100, 1986.

LITTLE, D.C.; HULATA, G. Strategies for tilapia seed production. In: BEVERIDGE, M.C.M.; MCANDREW, B.J. (Ed.) Tilapia: biology and explotation. Dordrecht: Kluwer Academic Publisher, 2000. p.226-326.

MACINTOSCH, D.J.; LITTLE, D.C. Nile tilapia (Oreochromis niloticus). In: BROMAGE, N.R.; ROBERTS, R.J. (Ed) Broodstock management and egg and larval quality. London: Blackwell Science Ltd, 1995. p.277-320.

MATAVELI, M.; MORAES, G.V.; STREIT JR., D.P. et al. Avaliação da qualidade do sêmen de tilápia-do-Nilo (Oreochromis niloticus), linhagem Chitralada, suplementada com diferentes concentrações de vitamina C. Boletim do Instituto de Pesca, v.33, n.1, p.1-7, 2007.

MEURER, F.; BOMBARDELLI, R.A.; HAYASHI, C. et al. Grau de moagem dos alimentos em rações para a tilápia-do-Nilo (Oreochromis niloticus) durante o período de reversão sexual Acta Scientiarum, v.27, n.1, p.81-85, 2005.

MEURER, F.; HAYASHI, C.; BARBERO, L.M. et al. Farelo de soja na alimentação de tilápias-do-nilo durante o período de reversão sexual. Revista Brasileira de Zootecnia, v.37, n.5, p.791794, 2008

MORAES, G.V.; STREIT JR., D.P.; RIBEIRO, R.P. et al. Ação de diferentes indutores reprodutivos hormonais no aparecimento de anormalidades morfológicas em espermatozóides de piavuçu (Leporinus macrocephalus), curimbatá (Prochilodus lineatus) e carpa comum (Cyprinus carpio). Boletim do Instituto de Pesca, v.30, n.2, p.109-116, 2004. 
MORTIMER, D.Sperm preparation methods. Journal of Andrology, v.21, n.3, p.357-366, 2000.

MURGAS, L.D.S.; FRANCISCATTO, R.T.; SANTOS, A.G.O. Avaliação espermática pós-descongelamento em piracanjuba Brycon orbignyanus (Vallenciennes, 1849). Revista Brasileira de Zootecnia, v.32, n.6, p.1810-1814, 2003

MYLONAS, C.C.; GISSIS. A.; MAGNUS. Y. et al. Hormonal changes in male white bass (Morone chysops) and evaluation of milt quality after treatment with a sustained-release GnRHa delivery system. Aquaculture, v.153, p.301-311, 1997.

NATIONAL RESEARCH COUNCIL - NRC. Nutrient requeriment of fish. Washington, D.C.: National Academy Press, 1993. $115 \mathrm{p}$.

NAVARRO, R.D.; LANNA, E.A.T.; DONZELE, J.L. et al. Níveis de energia digestível da dieta sobre o desempenho de piauçu (Leporinus macrocephalus) em fase pós-larval. Acta Scientiarum Animal Science, v.29, n.1, p.109-114, 2007.

NAVARRO, R.D.; MATTA, S.L.P; LANNA, E.A.T. et al. Níveis de energia digestível na dieta de piauçu (Leporinus macrocephalus) no desenvolvimento testicular em estágio pós-larval. Zootecnia Tropical, v.24, n.2, p.153-163, 2006.

OLIVIERA SILVA, F.C.; DONZELE, J.L.; FONSCECA, C.C. et al. Efeito de energia digestível da ração sobre os parâmetros reprodutivos de suínos machos inteiros e fêmeas. Revista Brasileira de Zootecnia, v.27, n.5, p.965-973, 1998.

PEREIRA, T.S.; FABREGAT, T.E.H.P.; FERNANDES, J.B.K. et al. Selênio orgânico na alimentação de matrizes de tilápia-doNilo (Oreochromis niloticus L.). Acta Scientiarum.Animal Sciences, v.31, n.4, p.433-437, 2009.

PEZZATO, L.E.; BARROS, M.M.; FRACALOSSI, D.M. et al. Nutrição de peixes. In: CYRINO, J.E.; URBINATI, E.C.; FRACALOSSI, D.M. et al. (Eds.) Tópicos especiais em piscicultura de água doce tropical intensiva. São Paulo: TecArt, 2004. p.75-170.

PEZZATO, L.E.; BARROS, M.M.; PEZZATO, A.C. et al. Relación energia:proteína en la nutrición de alevinos de piauçu (Leporinus macrocephalus). Revista de Medicina Veterinaria y Zotecnia, v.47, n.1, p.2-7, 2000.

RANA, K. Preservation of gametes. In: BROMAGE, N.R.; ROBERTS, R.J. (Eds.) Broodstock management and egg and larval quality. London: Blackwell Science Ltda., 1995. p. $53-75$.

REDDING, J.M.; PATIÑO, R. Reproductive physiology. In: EVANS, D.H. (Ed.) The physiology of fishes. Boca Raton: CRC Press, 1993. p.503-562.

RINCHARD, J.; MBAHINZIREK, G.; DABROWSKI, K. et al. Effects of dietary cottonseed meal protein level on growth, gonad development and plasma sex steroid hormones of tropical fish tilapia Oreochromis sp. Aquaculture International, v.10, p.11-28, 2002.

ROSS, L.G. Environmental physiology and energetics. In: BEVERDGE, M.C.M.; MCANDREW, B.J. (Eds.) Tilapias: biology and exploitation. London: Kluwer Academic Publishers, 2000. p.89-128.
RURANGWA, E.; KIME, D.E.; OLLEVIER, F. et al. The measurement of sperm motility and factors affecting sperm quality in cultured fish. Aquaculture, v.234, p.1-28, 2004.

RUYTER, B.; MOYA-FALCÓN, C.; ROSENLUND, G. et al. Fat contend and morphology of liver and intestine of Atlantic salmon (Salmo salar): Effects of temperature and dietary soybean oil. Aquaculture, v.252, p.441-452, 2006.

SALARO, A.L.; PEZZATO, L.E.; BARROS, M.M. et al. Desempenho e espermatogênese de alevinos de tilápia alimentados com farelo ou farinha de semente de algodão. Pesquisa Agropecuária Brasileira, v.34, n.3, p.449-457, 1999.

SANTIAGO, C.B.; LARON, M.A. Growth and fry production of Nile tilapia, Oreochromis niloticus (L.), on different feeding schedules. Aquaculture Research, v.33, p.129-136, 2002.

STREIT JR., D.P.; MORAES, G.V.; RIBEIRO, R.P. et al. Avaliação de diferentes técnicas para coloração de sêmen de peixe. Arquivos de Ciências Veterinárias e Zoologia da UNIPAR, v.7, n.2, p.157-162, 2004.

STREIT JR., D.P.; MORAES, G.V.; RIBEIRO, R.P. et al. Effects of three different sources of pituitary extract on gonadal inducer in male and female pacu (Piaractus mesopotamicus). Acta Scientiarum.Animal Science, v.27, n.4, p.439-447, 2005.

STREIT JR., D.P.; RIBEIRO, R.P.; MORAES, G.V. et al. Características qualitativas do sêmen de pacu (Piaractus mesopotâmicus) após indução hormonal. Bioscience Journal, v.22, n.3, p.119-125, 2006

TACON, P.; NDIAYE, P.; CAUTY, C. et al. Relationships between the expression of maternal behavior and ovarian development in the mouthbrooding cichlid fish Oreochromis niloticus. Aquaculture, v.146, p.261-275, 1996.

TAYLORS, P.W.; ROBERTS, S.D. Clove oil: an alternative anesthetic for aquaculture. North American Journal of Aquaculture, v.61, p.150-155, 1999.

TURNER, G.F.; ROBINSON, R.L. Reproductive biology, mating systems and parental care. In: BEVERIDGE, M.C.M.; MCANDREW, B.J. (Ed.) Tilapias: Biology and explotation. London: Kluwer Academic Publishers, 2000. p.33-58.

VAN DER KRAAK, G.; CHANG, J.P.; JANZ, D.M. Reproduction. In: EVANS, D.H. (Ed.) The physiology of fishes. 2.ed. Boca Raton: CRC Press, 1997. p.465-490.

VASSALO-AGIUS, R.; IMAIZUMI, H.; WATANABE, T. et al. The influence of astaxanthin supplemented dry pellets on spawning of striped jack. Fisheries Science, v.67, p.260-270, 2001a.

VASSALO-AGIUS, R.; WATANABE, T.; YOSHIZAKI, G. et al. Quality of eggs and spermatozoa of Rainbow trout fed an n3 essential fatty acid-deficient diet and its effects o the lipid and fatty acid components of eggs, semen and livers. Fisheries Science, v.67, p.818-827, $2001 \mathrm{~b}$.

VAZZOLER, A.E.A.M. Biologia da reprodução de peixes teleósteos: teoria e prática. Maringá: EDUEM, 1996. 169p.

WATANABE, T.; VASSALO-AGIUS, R. Broodstock nutrition research on marine finfish in Japan. Aquaculture, v.227, p.35-61, 2003. 